\title{
THE INCIDENCE AND CHARACTERISTICS OF DYSTHYROIDISM AS AN EX-SERVICE DISABILITY
}

\author{
WITH ESPECIAL REFERENCE TO THE FINDINGS IN DISCHARGED \\ SOLDIERS AND SAILORS, EXAMINED FOR THE BUREAU OF WAR RISK \\ INSURANCE (NOW THE VETERANS' BUREAU), District No. $2 *$
}

JAMES H. HUDDLESON, M.D.

Assistant Attendant Neurologist, Broad Street Hospital, and Neuropsychiatrist, Veterans' Bureau, District No. 2

AND

M. PRENTISS BAILEY, M.D.

Neuropsychiatrist, Veterans' Bureau, District No. 2

NEW YORK

The literature of the late World War early recorded a remarkable frequency of hyperthyroid conditions as compared with their incidence in times of peace. This was noted among combatants and noncombatants in military service, and in the civil population as well. Disabled ex-service men and women who had been invalided, and those less severely disabled in service who had been discharged in good condition but who had had a relapse, have together constituted the examinees of the federal Bureau of War Risk Insurance (the Veterans' Bureau since Aug. 9, 1921) ; here also the incidence of hyperthyroidism has been above normal. $\mathrm{H}$. W. Wright, ${ }^{1}$ in a review of postbellum neuroses, separates a group of "secondary neurasthenic states," including those complicated by thyrotoxicoses, or those in which some disorder of the thyroid is a prominent feature. It seemed worth while to review the war literature on dysthyroidisms in the light of postwar conditions - using the term "dysthyroidism" broadly, to include all forms of thyroid anomaly. .

\footnotetext{
* Permission to publish these data has been granted by Dr. T. M. Baird, medical officer in charge, New York City Station, U. S. Veterans' Bureau, District No. 2. We also wish to express our appreciation of the helpful coöperation of Dr. T. J. Vosburgh, chief neuropsychiatrist, and Katherine D. Smith, special assistant.

1. Wright, Harold W.: Postbellum Neuroses; a Clinical Review and Discussion of their Mechanism, Arch. Neurol. \& Psychiat. 3:429 (April) 1920.
} 
For 1916, before the United States entered the war, a representative clinic $^{2}$ of New York City ${ }^{3}$ reported 0.92 per cent. of ductless gland disorders among all neuropsychiatric cases; in 1918, that percentage rose to 3.01, but dropped in 1919 to 1.75. Among the Bureau of War Risk Insurance claimants examined at this office during the first half of 1921, various ductless gland disorders (thyroid, thymic, pituitary, polyglandular, etc.) have been found in 3.93 per cent. of all neuropsychiatric cases, or thyroid disorders in 3.36 per cent. Patients with a neuropsychosis and a thyroid disorder simultaneously, made up 0.59 per cent. of the total number of cases (medical, surgical, etc.).

It is clear that the civilian rate of dysthyroidism incidence rose during the war and has fallen since. The ex-service rate is still high. Statistics are not yet available for comparing its incidence year by year in this district. Surgeon J. G. Townsend ${ }^{4}$ of District No. 4 reported earlier this year that "the estimated total neuropsychiatric disabilities present in ex-service men directly traceable to military service is 76,588 , this number being further classified as follows . . endocrinopathies 4,823 . . " These figures amount to a percentage of 6.29 . Our own ratio ( 3.93 per cent.) is much lower, though still high. A large part of this discrepancy would be taken up by the excessive incidence of goiter in districts ${ }^{5}$ in which the endemic type is more prevalent than here. The remaining difference can be construed as evidence-further evidence will be adduced laterpointing toward a beginning post-war decline in total dysthyroidisms. While "the peak for the neuropsychiatric cases is not expected to be reached until 1926," 4 the relative frequency of hyperthyroidism should be lessening already.

2. The New York Neurological Institute Reports enumerate their ductless gland cases together and not by subdivisions, but it may reasonably be assumed that the great majority are cases of dysthyroidism. The 1920 Report cannot be used for comparison since the Institute added a special endocrinologic clinic about the end of 1919, which soon attracted a disproportionate number of cases of ductless gland disorders. The Institute figures are those for males only, while the Bureau figures include a few females; the comparison is approximately correct, which it would not be if the Institute figures for both sexes were taken, since all authorities agree that the incidence of ductless gland disorders is, caeteris paribus, far greater in females than in males.

3. Seventh Annual Report of the Neurological Institute of New York for the Year Ended November 30, 1916. Tenth Annual Report of the Neurological Institute of New York for the Year Ended November 30, 1919.

4. Townsend, J. G.: Rehabilitation of the Ex-Service Personnel of the World War, Mil. Surgeon 48:127 (Feb.) 1921.

5. Addis, T., and Kerr, W. J.: The Relative Frequency in Recruits With and Without Thyroid Enlargement of Certain Signs and Symptoms which Occur in Neurocirculatory Asthenia, Arch. Int. Med. 23:316 (March) 1919. 
French reports particularly have called attention to hyperthyroidism immediately referable to various forms of shock. Léniez ${ }^{6}$ describes three cases occurring before 1910, in which cerebral concussion was followed in from one to three months by definite exophthalmic goiter. The same writer saw a number of mild cases of exophthalmic goiter, "formes frustes," following injuries of the head and without previous signs; the struma was seldom large, and true exophthalmos was infrequent. R. Blondel ${ }^{7}$ comments on the increase of exophthalmic goiter during the war, both in women and in men. G. Étienne and G. Richard ${ }^{8}$ conclude, both from their own observations and from those of others, that cases of exophthalmic goiter occur rather often in active military service. L. Bérard ${ }^{9}$ found many cases of exophthalmic goiter, both mild and severe, in military men between the ages of 20 and 45 ; he rarely saw those in civil life. On the German side, $\mathrm{H}$ : Klose ${ }^{10}$ treats it as an accepted fact that exophthalmic goiter has been precipitated frequently by the war; he also suggests that the chemical action of gases may have had a share in the etiology. Among American authorities, Crile ${ }^{11}$ makes the statement that "iodin alone, adrenalin alone, thyroid extract alone, emotion, exertion, or infection alone, each causes a 'Kinetic Drive' with phenomena similar to those of exophthalmic goiter." According to Harlow Brooks," "emotional shock, fright, or mental trauma is too well established in the etiology of Graves' disease to admit of question."

Hyperthyroidism and war inevitably call to mind the many discussions and investigations of "soldier's heart"- "neurocirculatory asthenia," "effort syndrome," "disordered action of the heart." Was it or was it not hyperthyroidism? Without laboratory tests, we have been disinclined to take a definite stand on this matter. Such patients appearing for examination have tended to separate into three groups 1916.

6. Léniez: Sur le goitre exophthalmique traumatique, Progrès méd. 31:215,

7. Blondel, R.: L'accroissement d'une cause de stérilité féminine depuis la guerre par le développement de la maladie de Basedow, Bull. gén. d. thérap. $170: 816,1918-1919$.

8. Etienne, G., and Richard, G.: Maladie de Basedow et émotions de bombardements, Bull. et mém. Soc. méd. d. hôp. de Paris, Ser. 3 42:1196 (Dec. 20), 1918.

9. Bérard, L.: La maladie de Basedow et la guerre, Bull. Acad. de méd., Paris 76:428 (Nov. 28) 1916.

10. Klose, Heinrich: Der Kriegs-Basedow Pathogenese, Typen, Verlauf und militärärztliche Bewertung, Med. Klin. 14:1199 (Dec. 8) 1919.

11. Crile, G. W.: A Physical Interpretation of Shock, Exhaustion and Restoration, London, 1921, p. 171.

12. Brooks, Harlow: Hyperthyroidism in the Recruit, Med. Rec. 93:476 (March 16) 1918. 
instead of remaining together, the cases of some being diagnosed by cardiac examiners and the patients ordered proper treatment without being referred to the neurologists, while others are so referred, but may or may not be given a hyperthyroid diagnosis in addition to that of a cardiac dysfunction, according to the prominence of signs of hyperthyroidism. It would be impossible to estimate the proportions of these three groups. Occasionally we have labeled a case "hyperthyroidism," when the patient's service diagnosis was known to have been "irritable heart" (or an equivalent term); but the thyroid and neurocirculatory diagnoses have not been used interchangeably.

Divergent views on the proper classification of this "irritable heart of soldiers" may be illustrated by referring to the studies of Thomas Lewis, ${ }^{13}$ T. B. Barringer, ${ }^{14}$ T. A. Smith and D. Bovaird, ${ }^{15}$ T. Addis and W. J. Kerr, ${ }^{5}$ L. M. Warfield and F. M. Smith, ${ }^{16}$ F. W. Peabody, C. C. Sturgis, J. T. Wearn, H. D. Clough, and Edna H. Tompkins, ${ }^{17}$ in favor of discrimination between hyperthyroidism and irritable heart; and to those of Harlow Brooks, ${ }^{12} \mathrm{~J}$. H. Carroll ${ }^{18}$ and G. Railliet, ${ }^{19}$ who prefer to consider the two conditions identical. The wartime work of Peabody and his collaborators was particularly exhaustive, including tests of epinephrin sensitiveness and basal metabolism, and finally led them to the conclusion that hyperthyroidism did not play a significant rôle in the production of the syndrome known as the "irritable heart of soldiers."

13. Lewis, Thomas: Med. Res. Committee, Special Rept. Ser. No. 8, London, 1917.

14. Barringer, T. B., Jr.: "Disordered Action of the Heart" in British Soldiers, J. A. M. A. 69:1726 (Nov. 17) 1917.

15. Smith, Thayer A., and Bovaird, David: Irritable Heart or Effort Syndrome, Am. J. M. Sc. 156:872 (Dec.) 1918.

16. Warfield, L. M., and Smith, F. M.: Studies on Irritable Heart. II. Etiology of Irritable Heart, J. Lab. \& Clin. Med. 5:75, 1919-1920.

17. Peabody, F. W.; Clough, H. D.; Sturgis, C. C.; Wearn, J. T., and Tompkins, E. H.: Effects of the Injection of Epinephrin in Soldiers with "Irritable Heart," J. A. M. A. 71:1912 (Dec. 7) 1918. Wearn, Joseph T., and Sturgis, Cyrus C.: Studies on Epinephrin. I. Effects of the Injection of Epinephrin in Soldiers with "Irritable Heart," Arch. Int. Med. 24:247 (Sept.) 1919. Tompkins, Edna H.; Sturgis, Cyrus C., and Wearn, Joseph T.: Studies on Epinephrin. II. The Effect of Epinephrin on the Basal Metabolism in Soldiers with "Irritable Heart," in Hyperthyroidism and in Normal Men, Ibid., p. 269. Peabody, Francis W.; Wearn, Joseph T., and Tompkins, Edna H.: Basal Metabolism in Cases of the "Irritable Heart of Soldiers," Med. Clin. North America (Sept.) 1918.

18. Carroll, John H.: Neurocirculatory Asthenia (Soldiers' Heart), Am. J. M. Sc. 158:35 (July) 1919.

19. Railliet, G.: Basedowisme post-émotionnel et hypertrophie des parotides, Bull. et mém. Soc. méd. đ. hôp. de Paris, Ser. 3 42:1151 (Dec. 6) 1918. 
AUTHORS' MATERIAL

The period covered by our survey dates from Jan. 1, 1921, to July 1, 1921; the cases are those of all former ex-service men and women in this district that had filed claims for compensation from the government on account of disabilities acquired in connection with their military service, and who were consequently examined by the Bureau of War Risk Insurance at the headquarters of District No. 2 in New York City. We include all persons seen at this central office, whether coming from the city or sent in from greater distances for special examinations, and also include city house calls made from the central office. Cases of incidental complaints among war risk beneficiaries in federal training for rehabilitation (urıder the then "Federal Board for Vocational Education") are not included.

For this period the daily reports of general initial examinations and general reexaminations show a total of 18,675 , exclusive of special examinations and consultations. In determining the number of persons examined, which must be less than the total number of examinations because many men received complete reexaminations within the six months, a review of 500 cases showed that 421 of that number were examined once during the set period, seventy-one twice, seven three times, and one four times. This is at the rate of 1,176 examinations per 1,000 persons. Proportionately, the total of 18,675 general examinations represent 15,880 persons examined. Of these, 2,797 claimants received neuropsychiatric examinations in addition to the general examinations (that is, approximately 3,290 neuropsychiatric examinations were made). Among those 2,797, the neuropsychiatric total, ninety-four examinees were found to have some form of thyroid disorder in addition to their nervous or mental complaint. A few goitrous cases with no subjective or objective neurologic symptomatology may have escaped the neuropsychiatric section, but it has been the policy to require a neuropsychiatric examination in all cases of endocrinopathy.

CLASSIFICATION OF CASES OF THYROID DYSFUNCTION

Cases that make up a series showing thyroid dysfunction can be theoretically separated by symptoms into four general groups: (1) toxic thyroid, (2) dysthyroid (in the narrowest sense), (3) hypothyroid, and (4) simple goiter. Group 2 connotes cases of disturbed thyroid activity in which neither hyper-activity nor hypo-activity can be said to dominate the picture. None of these cases was observed. Group 3 is self-explanatory; similarly, no examples were found. (Very few patients had been operated on, and those rather recently.) Group 4 comprises cases of goiter, whether cystic or adenomatous, in which no evidence of dysfunction was determined but in which there was some concomitant neurologic or psychiatric disorder; only one case could be so classified. 
Group 1, comprising ninety-three cases, calls for special attention and subdivision. Various fundamenta divisionis are found in the literature. We have taken the well-recognized clinical types, exophthalmic and toxic nonexophthalmic, with a transitional group of "mixed" cases. Our data do not justify an attempt to classify by the presence or absence of hyperplasia. ${ }^{20}$ Similarly the conceptions ${ }^{10}$ of struma basedowiana as opposed to struma basedowificata, and those of idiopathic and symptomatic exophthalmic goiter, have been kept in view while not being used primarily. "Sympathicotonic" and "vagotonic," 21 however, are feasible as well as valuable conceptions; while their limits are not strictly coterminous with those of toxic exophthalmic and toxic nonexophthalmic goiter, they are sufficiently so to warrant mutual comparisons among findings classified by the two sets of criteria. The nature of examining work in the Bureau of War Risk Insurance has not permitted intensive study of the symptomatology of any group, nor has there been an opportunity to determine reactions to epinephrin injection, thyroid feeding, basal metabolism or other tests. These have been conducted only in the Public Health Service hospitals, or others to which patients could be referred for intensive study and treatment, and are outside the scope of this paper.

Five exophthalmic, sixty-three toxic nonexophthalmic, and twentyfive mixed, made up the total number of toxic cases. The criteria of classification corresponded approximately to those familiar as "sympathicotonic" and "vagotonic." There were no cases of pure sympathicotonia or vagotonia. The cases grouped as exophthalmic were characterized, mainly, by a marked degree of exophthalmos and of tachycardia, and by the absence of hyperhidrosis.

In the mixed group, 68 per cent. of the patients exhibited more or less exophthalmos, and 36 per cent. positive von Graefe and Stellwag signs. In 32 per cent., the pulse rate sitting was 100 or over; 52 per cent. showed well marked hyperhidrosis. In the toxic nonexophthalmic group, 15 per cent. showed a tendency toward exophthalmos, and 20 per cent. had a pulse rate, sitting, of 100 or over. Forty per cent. had typical hyperhidrosis.

Definite visible and palpable thyroid enlargement was present in approximately one half of the hyperthyroid cases, taking the three groups together; it was more frequent in the nonexophthalmic than in the others. The usual tendency toward a more marked affection of the right lobe than of the left was verified. Typical fine hyperthyroid tremor was the rule.

20. Plummer, Henry S.: The Function of the Thyroid, Normal and Abnormal, Trans. Ass. Am. Phys. 31:128, 1916.

21. Eppinger and Hess: Vagotonia, trans. by Kraus, Walter Max, and Jelliffe, Smith Ely, J. Nerv. \& Ment. Dis. Monograph, N. Y., 1915. 
Psychotic tendencies, when present, were in the direction of mild depressed states. M. S. Woodbury ${ }^{22}$ remarks that thyrotoxic psychosis probably does not deserve a separate classification, but adds that in cases of patients not actually insane a definite mental and nervous picture does appear, differing somewhat in type according to the type of dysthyroidism present. He finds practically all patients with toxic cases "nervous" in some degree, from moderate nervous hypertension to extreme restlessness, excitability and irritability, all these symptoms being less striking in nonexophthalmic than in exophthalmic goiter. Our findings are identical in these respects. His conclusion that a depression of moderate duration is commoner in toxic nonexophthalmic than in toxic exophthalmic cases could not be verified, since that symptom was observed in only five of the ninetythree cases; these five patients, however, all had toxic nonexophthalmic goiter. Next to "nervousness," the commonest single psychoneurotic symptom was insomnia, occurring in one fifth of out series.

\section{ETIOLOGY}

An acute infection preceding the onset of hyperthyroidism, or a chronic infection concurrent with it, whether in a causal relationship or not, appeared in the histories of approximately three quarters of the series. With the exceptions of pharyngitis or tonsillitis (in six cases), influenza (in nine), and chronic bronchitis (in fourteen), no one infection was associated with more than one or two cases of hyperthyroidism. C. A. Roeder ${ }^{23}$ reported a number of cases of toxic goiter "developing rapidly and immediately following the infection" (epidemic influenza). J. H. Carroll ${ }^{18}$ noted that "men ill with trench fever uniformly evidenced marked vagal phenomena during the febrile and convalescent stages." Trench fever did not appear at all in our series. It is a fair assumption that many of the patients with hyperthyroid cases caused by the war, at least of the vagotonic or toxic nonexophthalmic type, have made good recoveries.

Although quite in agreement with those who ascribe etiologic importance to shell-fire and gassing, we have drawn no conclusions from the presence or absence of these causative factors on account of their uncertain history. Gas is too frequently named by the patient now as a cause for all ills, even more so than in the American Expeditionary Forces. Hyperthyroidism arising in gas warfare may be referable to gas intoxication directly, or may be part of a "gas syndrome" or "gas neurosis" (differentiated by Schwab ${ }^{24}$ ) considered psychoneurotically.

22. Woodbury, M. S.: The Psycho-Neurotic Syndrome of Hyperthyroidism, J. Nerv. \& Ment. Dis. 47:401 (June) 1918.

23. Roeder, C. A.: Toxic Goiter Following Epidernic Influenza, Surg. Gyn. \& Obst. 30:357 (April) 1920.

24. Schwab, Sidney I.: The War Neuroses as Physiologic Conservations, Arch. of Neurol. \& Psychiat. 1:579 (May) 1919. 
High explosive shelling with possibly resultant ${ }^{24}$ "concussion syndrome," "concussion neurosis," or other psychoneurosis, which may be accompanied by hyperthyroidism, can rarely be reckoned positively present or positively absent in a given case history.

\section{TREATMENT AND COURSE}

Operations on the thyroid were performed in only eight cases, with results showing no significant difference between patients treated surgically and those treated medically. In either instance, any governmental control over treatment is uncertain at best. Many examinations, being initial during the period studied, afforded no bases for comparisons; many others, not initial, showed no net gain or loss; about one quarter of the total were marked definitely "better" (60 per cent.) or "worse" ( 40 per cent.), and this predominance of improvement applied to each of the three subgroups, toxic nonexophthalmic, exophthalmic and mixed. Most ( 78 per cent.) of the series were rated by the examiners as "feasible for vocational training," but the success of those persons who have undertaken it cannot be determined for some time.

Many factors other than strictly medical or surgical considerations will necessarily influence the further course of the disease in any one of these cases. Almost all of the patients are a priori psychoneurotic and prone to chronic invalidism; their youth is favorable, but their compensability may be a hindrance; even intensive handling of psychoneurotic patients, as summarized by Richards, ${ }^{25}$ scarcely promises brilliant results.

Von Noorden ${ }^{26}$ maintained that neither the purely vagotonic nor the purely sympathicotonic type of exophthalmic goiter was accompanied by psychopathologic symptoms; these were confined to mixed types of the disease. The more prevalent conception today is that all cases of exophthalmic goiter are more or less mixed and may be more or less psychoneurotic. In our series, the "mixed" cases are those in which neither exophthalmic (sympathicotonic) nor nonexophthalmic (vagotonic) tendencies are definitely predominant.

\section{SUMMARY}

To summarize, our material consisted of ninety-four consecutive outpatient cases, clinically examined, of war veterans suffering from thyroid dysfunction accompanied by some neuropsychiatric disorder. We conclude: (1) that the incidence of dysthyroidism, increased by

25. Richards, Esther L.: A Study of the Invalid Reaction, Arch. Neurol. \& Psychiat. 2:393 (Oct.) 1919.

26. Von Noorden, Karl: Zur Kenntnis der Vagotonischen und Sympathikotonischen Fälle von Morbus Basedowii, Kiel, 1911. 
the war, is now on the decline but has not yet reached its prewar level ; (2) that the bulk of this increase is made up of toxic nonexophthalmic, vagotonic cases, and cases transitional between this and the sympathicotonic type; ( 3 ) that many causes for the increase have been variously operative, none predominating; and (4) that there is a distinct tendency toward improvement in all types of toxic cases caused by the war. 